\title{
REAPLICAÇÃO DE NITROGÊNIO NA MITIGAÇÃO DO EFEITO DA DESFOLHA EM DIFERENTES FASES FENOLÓGICAS DO MILHO
}

\author{
ANDRÉ PRECHLAK BARBOSA ${ }^{1}$, CLAUDEMIR ZUCARELI ${ }^{2}$, RODRIGO YOITI TSUKAHARA ${ }^{3}$ \\ EDSON GIOVANNI KOCHINSKI ${ }^{3}$ e JOSÉ HENRIQUE BIZZARRI BAZZO ${ }^{4}$
}

\author{
${ }^{1}$ Professor assistente da Pontifícia Universidade Católica do Paraná, andreprechlak@gmail.com \\ ${ }^{2}$ Professor adjunto da Universidade Estadual de Londrina, claudemircca@uel.br \\ ${ }^{3}$ Pesquisadorda FundaçãoABC,rodrigo@fundacaoabc.org.br,edson@fundacaoabc.org.br \\ ${ }^{4}$ Professordo Centro Universitário Filadélfia - Londrina-PR,agro.bazzo@gmail.com
}

Revista Brasileira de Milho e Sorgo, v.18, n.1, p. 30-46, 2019

\begin{abstract}
RESUMO - O manejo adequado da adubação nitrogenada para atenuar efeitos da perda de área foliar é uma solução pouco explorada. Portanto, objetivou-se avaliar, em campo, o efeito da reaplicação de nitrogênio e intensidade de desfolha em diferentes fases fenológicas sobre a incidência de grãos ardidos e o desempenho produtivo do milho. $\mathrm{O}$ delineamento experimental foi em blocos casualizados, com quatro repetições, em esquema fatorial $2 \times 7 \times 4+2$, sendo, a reaplicação de $\mathrm{N}$ em cobertura (0 e $\left.40 \mathrm{~kg} \mathrm{ha}^{-1}\right)$, os estádios fenológicos de desfolha (V2, V4, V6, V10, R1, R3 e R5), as intensidades de desfolha $(25,50,75$ e $100 \%)$ e dois controles adicionais $(0 \%$ de desfolha com e sem a reaplicação de N). As avaliações realizadas foram percentagem de grãos ardidos, massa de 100 grãos e produtividade de grãos. Os dados foram submetidos à análise de variância, testes de Tukey, Dunnett e regressão até $2^{\circ}$ grau $(\mathrm{p}<0,05)$. A reaplicação de nitrogênio após a desfolha atenua os efeitos desse estresse na massa e no rendimento total de grãos, com maior efetividade quando ocorre nos estádios vegetativos. O prejuízo ao desempenho produtivo em razão da desfolha é acentuado quando ocorre no florescimento e enchimento de grãos, pois desequilibra a relação fonte-dreno. A desfolha em estádios iniciais proporciona maior intensidade de grãos ardidos nas plantas de milho.
\end{abstract}

Palavras-chave: Adubação nitrogenada, Área foliar, Estádios fenológicos, Zea mays L.

\section{REAPPLICATION OF NITROGEN AS MITIGATION TO THE DEFOLIATION EFFECT AT STAGES OF MAIZE}

\begin{abstract}
The proper management of nitrogen fertilization to mitigate the effects of the loss of leaf area is poorly explored. Therefore, the present study evaluated the effect of nitrogen reapplication and defoliation intensity at different phenological stages on the incidence of rot grains and corn production performance. The experimental design was a randomized complete block with four replications, in a $2 \times 7 \times 4+2$ factorial scheme, with the reapplication of $\mathrm{N}$ topdressed ( 0 and $40 \mathrm{~kg} \mathrm{ha}^{-1}$ ), the defoliation stages (V2, V4, V6, V10, R1, R3 and R5), defoliation intensities (25, 50, 75 and $100 \%)$ and two additional controls ( $0 \%$ defoliation with and without reapplication of $\mathrm{N})$. Percentage of rot grains, mass of 100 grains and grain yield were evaluated. Data were subjected to analysis of variance, Tukey's, Dunnett's tests and regression up to grade $2(\mathrm{p}<0.05)$. Reapplication of nitrogen after defoliation attenuates the effects of this stress on the mass and the total yield of grains, with greater effectiveness in the vegetative stages. The damage to the productive performance due to defoliation was accentuated when occurred at the flowering and grain filling as it unbalances the source-drain relation. Depletion in the early stages caused higher occurrence of grain burned in maize plants.
\end{abstract} Keywords: Nitrogen fertilization, Leaf area, Phenological stages, Zea mays L. 
A ampla lacuna entre o rendimento real e o potencial da cultura do milho é explicada em parte pela diminuição da superfície fotossinteticamente ativa, ocasionada pela desfolha, provocada por fatores bióticos ou abióticos (Sangoi et al., 2012). A perda de área foliar compromete a atividade fisiológica das fontes produtoras de carboidratos, modificando a velocidade e a intensidade da senescência foliar, assim como o padrão de acúmulo de massa seca nos grãos (Uhart \& Andrade, 1995). Altera a relação fonte-dreno, e consequentemente a produtividade e a qualidade dos grãos produzidos, sendo ainda mais prejudicial em razão da restrita plasticidade foliar, prolificidade e capacidade de compensação de espaços que a cultura do milho apresenta (Pereira et al., 2012).

Híbridos de milho modernos apresentam menor porte, menor área foliar e ciclo precoce, que favorece o desempenho produtivo da lavoura, pelo incremento no índice de colheita (Kappes et al., 2011). Atualmente, cerca de $65 \%$ e $25 \%$ das cultivares de milho apresentam ciclo precoce e superprecoces, respectivamente, e vêm sendo mais cultivadas na segunda safra (Cruz et al., 2016). Essas características morfofisiológicas reduzem a tolerância desses genótipos a estresses, pois a menor área foliar associada ao ciclo curto dificulta a capacidade de recuperação da planta, ocasionando prejuízos acentuados mesmo com desfolhas menos intensas e em estádios iniciais da cultura.

O estádio em que ocorre o estresse de desfolha deve ser considerado, pois a maior sensibilidade do milho é relatada para o florescimento, com consequências negativas ao desenvolvimento da espiga, número e massa de grãos (Britz, 1982). Entretanto, Sangoi et al. (2014b) verificaram que a desfolha entre os estádios vegetativos V8 a V12 gera prejuízos significativos ao rendimento de grãos, dependendo do genótipo utilizado. É necessário ainda considerar o efeito da desfolha no período de maturação dos grãos de milho, em que ocorre a alocação dos fotoassimilados, fase essencial para a obtenção de alta produtividade.

A intensidade da desfolha também determina a severidade do estresse. Quanto maior o dano à área foliar, maiores são os prejuízos à cultura, seja na quantidade (Lima et al., 2010) ou na qualidade dos grãos (Blum et al., 2003; Pereira et al., 2012). O nitrogênio $(\mathrm{N})$ é conhecido por sua função estrutural nas plantas, e interfere em diversas características da planta relacionadas ao crescimento e desenvolvimento, que, direta ou indiretamente, afetam a produtividade e qualidade de grãos (Malavolta et al., 1997; Okumura et al., 2011).

Nesse contexto, o $\mathrm{N}$ pode ser utilizado para reversão de estresse por desfolha. Uma vez que têm ação comprovada sobre o crescimento e desenvolvimento de plantas, em especial das gramíneas, conforme citado por Magalhães et al. (2013). Entretanto esse potencial pode ser limitado pela época fenológica e intensidade de perda foliar.

Portanto, objetivou-se avaliar, em campo, o efeito da reaplicação de nitrogênio e da intensidade de desfolha em diferentes fases fenológicas da cultura do milho sobre a incidência de grãos ardidos e no desempenho produtivo.

\section{Material e Métodos}

O experimento foi conduzido no município de Castro-PR, em área com latitude de $24^{\circ} 51^{\prime} 49^{\prime}$, longitude de $49^{\circ} 56^{\prime} 61^{\prime}$, altitude de aproximadamente $1.020 \mathrm{~m}$. O clima da região é classificado segundo Köppen como Cfb (mesotérmico úmido, com boa dis- 
tribuição pluviométrica e verão temperado). Foi calculado o balanço hídrico para cultivos do período experimental, com determinação da evapotranspiração pelo método de Penman-Monteith (Figura 1a). Os dados referentes a insolação e temperatura do ar do período experimental (Figura 1b) foram obtidos na estação meteorológica da Fundação ABC (Castro-PR).
O solo da área experimental é classificado como Latossolo Bruno Distrófico típico (Santos et al., 2013). A coleta de amostras de solo foi realizada na profundidade de $0-20 \mathrm{~cm}$ antes da implantação do experimento. A análise química do solo apresentou os seguintes resultados: $\mathrm{pH}\left(\mathrm{CaCl}_{2}\right)=4,9 ; \mathrm{Al}^{+3}=1,0$ $\mathrm{mmol}_{\mathrm{c}} \mathrm{dm}^{-3} ; \mathrm{H}^{+}+\mathrm{Al}^{+3}=38 \mathrm{mmol}_{\mathrm{c}} \mathrm{dm}^{-3} ; \mathrm{MO}=28,3 \mathrm{~g}$
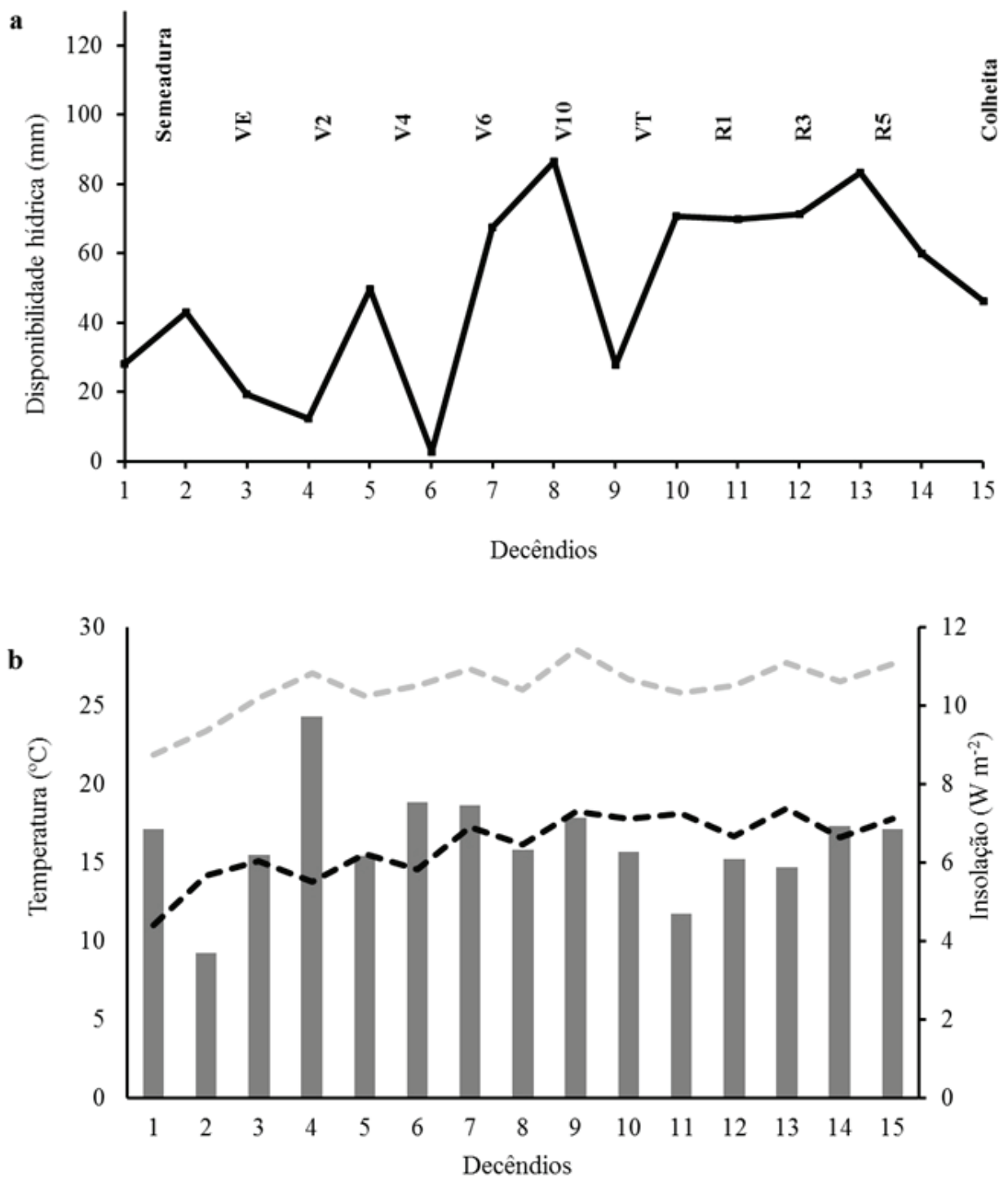

Figura 1. Balanço hídrico de cultivos segundo método de Penman-Monteith, com valores de disponibilidade hídrica (a) e valores médios de temperatura do ar (máxima e mínima) e insolação (b), referentes ao período experimental (18 de setembro a 16 de fevereiro). 
$\mathrm{dm}^{-3} ; \mathrm{P}$ (resina) $=35,7 \mathrm{mg} \mathrm{dm}^{-3} ; \mathrm{K}=1,2 \mathrm{mmol}_{\mathrm{c}} \mathrm{dm}^{-3}$; $\mathrm{Ca}=20,3 \mathrm{mmol}_{\mathrm{c}} \mathrm{dm}^{-3} ; \mathrm{Mg}=8,0 \mathrm{mmol}_{\mathrm{c}} \mathrm{dm}^{-3} ; \mathrm{CTC}=$ $67,5 \mathrm{mmol}_{\mathrm{c}} \mathrm{dm}^{-3}$ e $\mathrm{V}=43,3 \%$.

A adubação de base consistiu em $300 \mathrm{~kg} \mathrm{ha}^{-1}$ do formulado 13:31:00, que forneceu $39 \mathrm{~kg} \mathrm{ha}^{-1}$ de nitrogênio e $93 \mathrm{~kg} \mathrm{ha}^{-1}$ de fósforo. A adubação de cobertura, realizada em V6, foi de $300 \mathrm{~kg} \mathrm{ha}^{-1}$ de ureia, juntamente com $100 \mathrm{~kg} \mathrm{ha}^{-1}$ de cloreto de potássio, que forneceram $132 \mathrm{~kg} \mathrm{ha}^{-1}$ de nitrogênio e $60 \mathrm{~kg} \mathrm{ha}^{-1}$ de potássio. As sementes foram tratadas com dois inseticidas (tiametoxam + imidacropido), ambos na dose de $35 \mathrm{~g}$ i. a. para cada $20 \mathrm{~kg}$ de sementes. A semeadura foi realizada em 18 de setembro, em área cultivada em sistema de semeadura direta, sobre palha de aveia, utilizando-se o híbrido de milho P30F53, do tipo simples e com característica de ciclo precoce, sob espaçamento entre linhas de $0,8 \mathrm{~m}$ e população de 75.000 plantas ha-1.

Com o intuito de avaliar somente o efeito da redução da área foliar ocasionada pela desfolha mecânica, foram realizados manejos das plantas daninhas (tembotrione 52,5 g i.a ha-1 e atrazina 800 g i.a ha-1) dos insetos (tiametoxam 42,3 $\mathrm{g}$ i.a ha-1 e espinosade 28,8 g i.a ha ${ }^{-1}$ ), além de realizada aplicação de fungicida, azoxistrobina + ciproconazol nas doses de 60 e $24 \mathrm{~g}$ i. a ha ${ }^{-1}$, no estádio de V6 (Ritchie et al., 1993).

$\mathrm{O}$ experimento foi delineado em blocos casualizados, com 4 repetições, em esquema fatorial $2 \times 7 \times 4+2$. Os fatores estudados seguem descritos: dois tratamentos de reaplicação de nitrogênio (com e sem suplementação na dose de $40 \mathrm{~kg} \mathrm{ha}^{-1}$ de ureia, com $44 \%$ de $\mathrm{N}$ ), sete estádios fenológicos em que se realizou a desfolha (V2, V4, V6, VT, R1, R3 e R5) e quatro intensidades de desfolha $(25,50,75$ e 100\%). Para possibilidade de comparação foram produzidas duas parcelas consideradas testemunhas absolutas, com $0 \%$ de desfolha mecânica, uma com a reaplica- ção de $\mathrm{N}$ e outra sem a reaplicação de $\mathrm{N}$, que foi realizada no estádio VT.

A reaplicação de $\mathrm{N}$ (40 $\left.\mathrm{kg} \mathrm{ha}^{-1}\right)$ foi realizada imediatamente após a desfolha nos respectivos estádios estudados. A fonte de $\mathrm{N}$ utilizada foi a ureia aplicada a lanço em cobertura. As unidades experimentais foram constituídas por oito linhas com $5 \mathrm{~m}$ de comprimento cada, sendo considerada como área útil as quatro linhas centrais com $4 \mathrm{~m}$ cada uma, desconsiderando-se $0,5 \mathrm{~m}$ de cada extremidade, totalizando $12,8 \mathrm{~m}^{2}$

$\mathrm{Na}$ determinação do estádio fenológico de desfolha das plantas foi seguida a classificação de Ritchie et al. (1993). As intensidades de desfolha foram obtidas manualmente nos estádios V2 (17 de outubro), V4 (26 de outubro), V6 (07 de novembro), VT (28 de novembro), R1 (12 de dezembro), R3 (27 de dezembro) e R5 (03 de janeiro). A determinação da percentagem de desfolha foi feita por meio de medidas de comprimento e largura de todas as folhas verdes das plantas, e após a retirada de área foliar em cada percentagem específica foi realizada em todas as folhas, com auxílio de foice metálica em formato de "L". Novas folhas emitidas após a realização da desfolha foram mantidas.

As avaliações consistiram da determinação da massa de mil grãos, produtividade de grãos e percentagem de grãos ardidos. Para isso, após a debulha de todas as espigas colhidas na área útil das parcelas experimentais foi determinada a massa de mil grãos (MMG) (Brasil, 2009). A produtividade foi determinada com base na produção da área útil da parcela corrigida para $13 \%$ de umidade e convertida em $\mathrm{kg}$ $h^{-1}$. A percentagem de grãos ardidos foi determinada conforme procedimento proposto na Portaria $\mathrm{n}^{\mathrm{o}} 11$ do Ministério da Agricultura, de 12/04/1996 (Brasil, 1996). 
Os dados foram submetidos à análise de normalidade e homogeneidade dos resíduos pelo teste de Shapiro-Wilk e Bartlett, respectivamente, e analisados por ANOVA. Quando constatada diferença, os fatores qualitativos foram comparados (manejo de $\mathrm{N}$ pelo teste $\mathrm{F}$ e os estádios fenológicos pelo teste de Tukey) e o fator quantitativo (intensidades de desfolha) foi submetido a estudo de regressão. Para a comparação dos fatores estudados com os controles sem desfolha foi utilizado o teste de Dunnet. Todos os testes foram efetuados a 5\% de significância.

\section{Resultados e Discussão}

Após constatação de normalidade e homogeneidade dos resíduos, foi realizada a ANOVA, que demonstrou efeitos significativos para todas as variáveis analisadas, porém com respostas distintas em relação a ação isolada ou interação das fontes de variação estudadas (Tabela 1). A variável massa de mil grãos apresentou interação entre estádio da desfolha e intensidade de desfolha. Para a produtividade de grãos foi verificada interação dos três fatores estudados. Por fim, para a variável grãos ardidos, observou-se interação entre estádio da desfolha e reaplicação do $\mathrm{N}$ em cobertura (Tabela 1).

No que se refere a massa de mil grãos (Tabela 2), verificou-se que na menor intensidade de desfolha (25\%) não houve alteração da massa de grãos entre os estádios de desfolha. Com o incremento na intensidade de desfolha (50, 75 e 100\%), o acúmulo de fotoassimilados foi alterado, com menor massa dos grãos nos estádios entre o florescimento (VT) e a fase atenuativa da formação dos grãos (R5).

Essa resposta está associada à redução da fotossíntese por causa da perda de área foliar, que passou a fornecer menos fotoassimilados para os drenos (órgãos reprodutivos) e, ainda, à menor quantidade

Tabela 1. Resumo da análise de variância com os quadrados médios para as características avaliadas em função das percentagens de desfolha e reaplicação de nitrogênio em estádios fenológicos do milho.

\begin{tabular}{lllll}
\hline FV & GL & Produtividade & Massa de mil grãos & Grãos ardidos \\
\hline Estádio (E) & 6 & $133164425,56^{*}$ & $33581,55^{*}$ & $591,58^{*}$ \\
Nitrogênio (N) & 1 & $150852,54^{\mathrm{ns}}$ & $1698,02^{*}$ & $64,29^{\mathrm{ns}}$ \\
Desfolha (D) & 3 & $228397368,62^{*}$ & $45442,59^{*}$ & $126,33^{*}$ \\
E x N & 6 & $481114,07^{\mathrm{ns}}$ & $365,28^{\mathrm{ns}}$ & $95,85^{*}$ \\
E x D & 18 & $24382167,10^{*}$ & $7042,52^{*}$ & $44,39^{\mathrm{ns}}$ \\
N x D & 3 & $872816,28^{\mathrm{ns}}$ & $138,18^{\mathrm{ns}}$ & $19,55^{\mathrm{ns}}$ \\
E x N x D & 18 & $1206726,64^{*}$ & $261,41^{\mathrm{ns}}$ & $47,19^{\text {ns }}$ \\
Bloco & 3 & $541461,20^{\mathrm{ns}}$ & $213,77^{\mathrm{ns}}$ & $87,08^{\mathrm{ns}}$ \\
Erro & 165 & 373469,33 & 245,71 & 33,21 \\
\hline CV $(\%)$ & 5,99 & & 4,88 & 39,70 \\
\hline
\end{tabular}

CV: coeficiente de variação, FV: fonte de variação e GL: grau de liberdade, ${ }^{\text {ns: }}$ não significativo, *: significativo a $5 \%$ de probabilidade pelo teste F. 
de reservas acumuladas no colmo das plantas que responderam ao estresse por desfolha (Magalhães \& Durães, 2006).

O desbalanço da relação fonte-dreno e a perda de eficiência da distribuição de fotoassimilados nas plantas em razão da ocorrência de desfolha foram também relatados por Pereira et al. (2012) e Sangoi et al. (2002), como os principais motivos para a redução da massa de grãos de milho. Ressalta-se que a precocidade, que é uma característica preconizada nos atuais genótipos de milho, torna ainda mais grave o estresse decorrente de perda da área foliar, pois o menor ciclo proporciona menos tempo para a recuperação das plantas.

A resposta a intensidades de desfolha, nos diferentes estádios em que essa foi realizada (Figura 2), foi a não adequação de nenhum modelo para os estádios V2 e V4, nos quais a massa de grãos foi pouco alterada pelo incremento na intensidade de desfolha. Isso se justifica pela recuperação/expansão da área foliar após as desfolhas de V2 e V4, o que está relacionado com a diferenciação de folhas que ainda ocorre durante este período na cultura do milho.
No entanto, ao se avançarem os estádios de desenvolvimento da cultura, houve adequação linear decrescente em todos os demais estádios (V6, VT, R1, R3 e R5), com destaques para a menor taxa de decréscimo da massa de grãos ocorrida em V6 (Figura 2c), com cerca de $3 \mathrm{~g}$ a cada acréscimo de $10 \%$ na desfolha. Já para as fases posteriores, principalmente após a floração, houve maior taxa de redução, com maior prejuízo identificado em R3 (Figura $2 \mathrm{f}$ ), cerca de $6,5 \%$ menos massa de grãos, ou seja, 22,5 g a menos para cada $10 \%$ de incremento na desfolha.

Em R3 (grão leitoso), quando ocorreu a maior taxa de decréscimo na massa dos grãos, a maioria dos carboidratos estão sendo redirecionados na forma de sacarose para os grãos (Magalhães \& Durães, 2006). Sejam esses provenientes do resultado direto da fotossíntese vigente ou de reservas anteriormente acumuladas no colmo. Essa situação é condizente com o observado por Sangoi et al. (2012), que avaliaram a dinâmica de acúmulo e redistribuição de fotoassimilados em órgãos fontes (folhas e colmos) e drenos (inflorescências e grãos) em milho.

Tabela 2. Massa de mil grãos de milho, em função da intensidade de desfolha e estádios fenológicos distintos.

\begin{tabular}{lllll}
\hline \multirow{2}{*}{$\begin{array}{l}\text { Estádio } \\
\text { fenológico }\end{array}$} & $\mathbf{2 5}$ & $\mathbf{5 0}$ & $\mathbf{7 5}$ & $\mathbf{1 0 0}$ \\
\cline { 2 - 5 } & & \multicolumn{4}{l}{ Mercentagem de desfolha $\mathbf{( \% )}$} \\
V2 & $351,80 \mathrm{a}$ & $348,60 \mathrm{a}$ & $355,38 \mathrm{a}$ & $356,17 \mathrm{a}$ \\
V4 & $349,75 \mathrm{a}$ & $357,86 \mathrm{a}$ & $357,58 \mathrm{a}$ & $356,68 \mathrm{a}$ \\
V6 & $359,50 \mathrm{a}$ & $352,38 \mathrm{a}$ & $356,75 \mathrm{a}$ & $333,50 \mathrm{a}$ \\
VT & $342,78 \mathrm{a}$ & $324,88 \mathrm{bc}$ & $316,63 \mathrm{~b}$ & $284,00 \mathrm{~b}$ \\
R1 & $345,13 \mathrm{a}$ & $334,75 \mathrm{ab}$ & $316,88 \mathrm{~b}$ & $233,88 \mathrm{c}$ \\
R3 & $349,63 \mathrm{a}$ & $311,13 \mathrm{c}$ & $249,38 \mathrm{~d}$ & $232,38 \mathrm{c}$ \\
R5 & $339,38 \mathrm{a}$ & $323,50 \mathrm{bc}$ & $279,88 \mathrm{c}$ & $182,88 \mathrm{~d}$ \\
\hline
\end{tabular}

Médias seguidas de letras distintas na coluna diferem pelo teste de Tukey a $5 \%$ de probabilidade. 

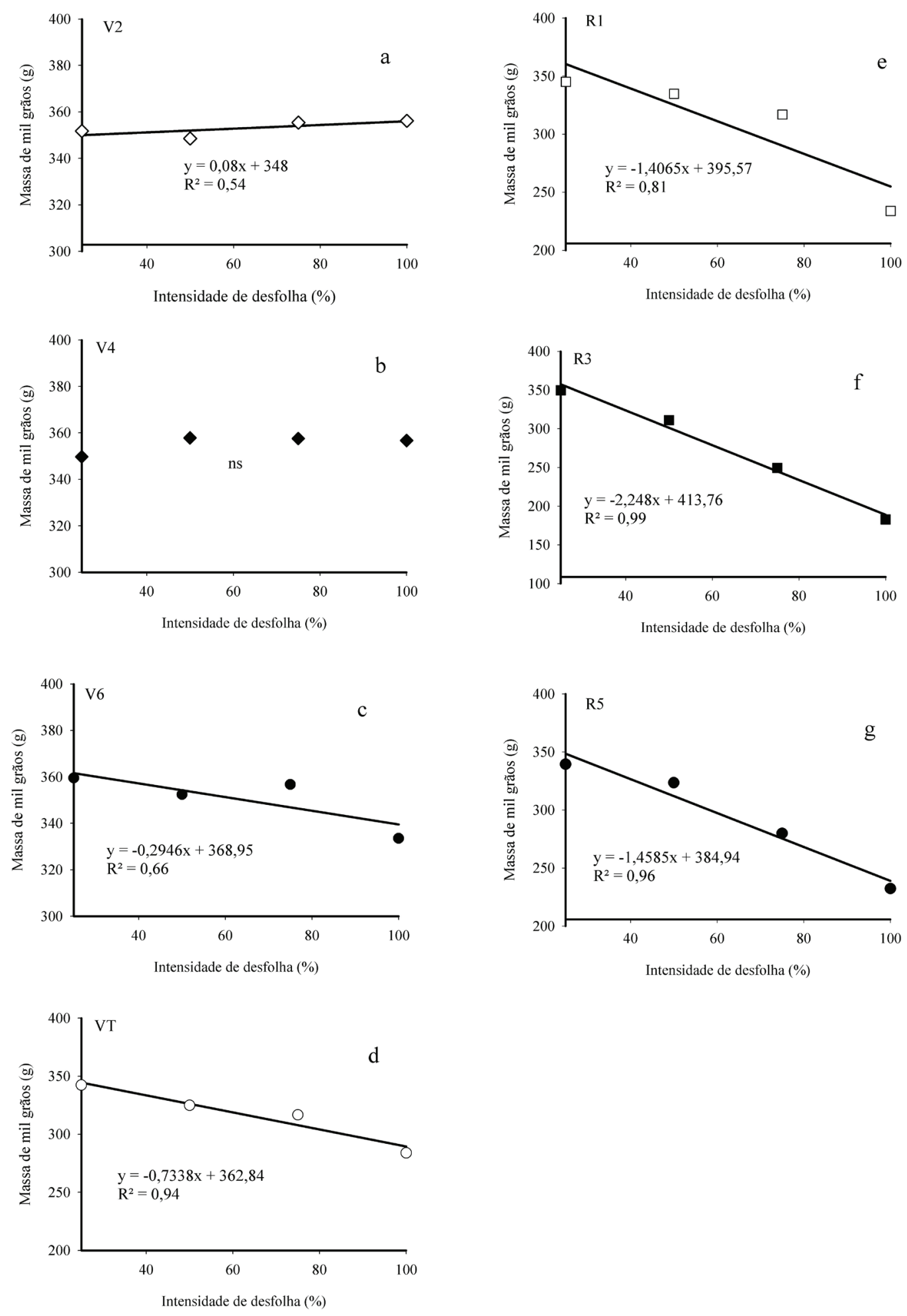

Figura 2. Massa de mil grãos de milho, em função da desfolha realizada nos estádios: V2 (a), V4 (b), V6 (c), VT (d), R1 (e), R3 (f) e R5 (g). 
Para o desdobramento da interação entre os estádios fenológicos de desfolha e reaplicação de nitrogênio em cobertura para a produtividade de grãos (Tabela 3), na menor percentagem de desfolha (25\%), os menores rendimentos de grãos foram obtidos quando a perda de área foliar ocorreu em VT na condição sem reaplicação de $\mathrm{N}$ e em R1 e R3 na condição com reaplicação.

Como aumento na intensidade da desfolha para $50 \%$ (Tabela 3), a redução da produtividade se manteve, com maiores perdas nos estádios VT, R1, R3 e $\mathrm{R} 5$, nessa ordem. Nas maiores percentagens de desfolhamento das plantas (75 e 100\%), foi mantida a fase de maior efeito negativo da perda de área foliar entre VT, R1 e R3. Essa resposta geral de maior dano entre pendoamento (VT), espigamento (R1) e enchimento de grãos (R3) é um reflexo da sensibilidade da cultura do milho a estresses na floração e logo após o florescimento.

A perda de área foliar no período reprodutivo ocasionou desbalanço na relação fonte-dreno das plantas, em razão da perda parcial ou total das folhas. E isso aconteceu na fase de exteriorização dos órgãos reprodutivos, fecundação de óvulos e enchimento dos grãos, que gerou perdas no número de grãos formados e na massa individual de grãos, com redução significativa no rendimento da cultura (Trogello et al., 2017).

As respostas supramencionadas se assemelham às obtidas por Sangoi et al. (2014b), que, ao testarem genótipos com ciclo e porte contrastantes e estádios fenológicos vegetativos de desfolha, verificaram maior dano à cultura quando as desfolhas foram realizadas próximas à fase de floração do milho. $\mathrm{O}$ mesmo foi verificado por Lima et al. (2010), que apenas tratando do período pós-floração identificaram o estádio R1 como o mais prejudicado pela redução de área foliar.
Pereira et al. (2012) destacam que o incremento na intensidade de desfolha é prejudicial à relação fonte-dreno das plantas de milho, o que ocasiona a redução de rendimento de grãos, assim como verificado no presente trabalho. Os mesmos autores corroboram, ainda, com a informação de que as fases mais sensíveis à ocorrência de desfolha são as de floração e enchimento de grãos.

Tratando-se, ainda, do desdobramento produtividade de grãos (Tabela 3), quando se compara a condição de reaplicação de $\mathrm{N}$ com a ausência de reaplicação verificam-se efeitos benéficos dessa reposição de $\mathrm{N}$, principalmente nos primeiros estádios vegetativos como V2, V4 e V6, para todas as intensidades de desfolha. No entanto, foi observado efeito positivo da adubação nitrogenada também em VT, na menor intensidade de desfolha.

Isso evidencia a capacidade desse nutriente em promover crescimento vegetativo nas plantas, participando da formação de componentes do metabolismo primário e secundário. Quando se relaciona a fotossíntese, essa é afetada pela perda de área foliar, a suplementação com $\mathrm{N}$ ocasiona, além do reestabelecimento parcial da área foliar, maior atividade fotossintetizante, já que é um dos elementos que constituem a molécula de clorofila. Esse fato, aliado ao crescimento e/ou recuperação da área foliar, favoreceu o desempenho das plantas (Queiroz et al., 2011).

No entanto, é relevante considerar que o efeito compensatório da reaplicação de $\mathrm{N}$ se restringiu, de maneira geral, aos estádios vegetativos, período em que as plantas estão em pleno desenvolvimento e ainda há tempo para a expressão da capacidade de compensação até a formação dos componentes de rendimento. Por esse motivo não se verificou recuperação das plantas pela reaplicação de $\mathrm{N}$ quando a desfolha ocorreu da floração em diante, para todas 


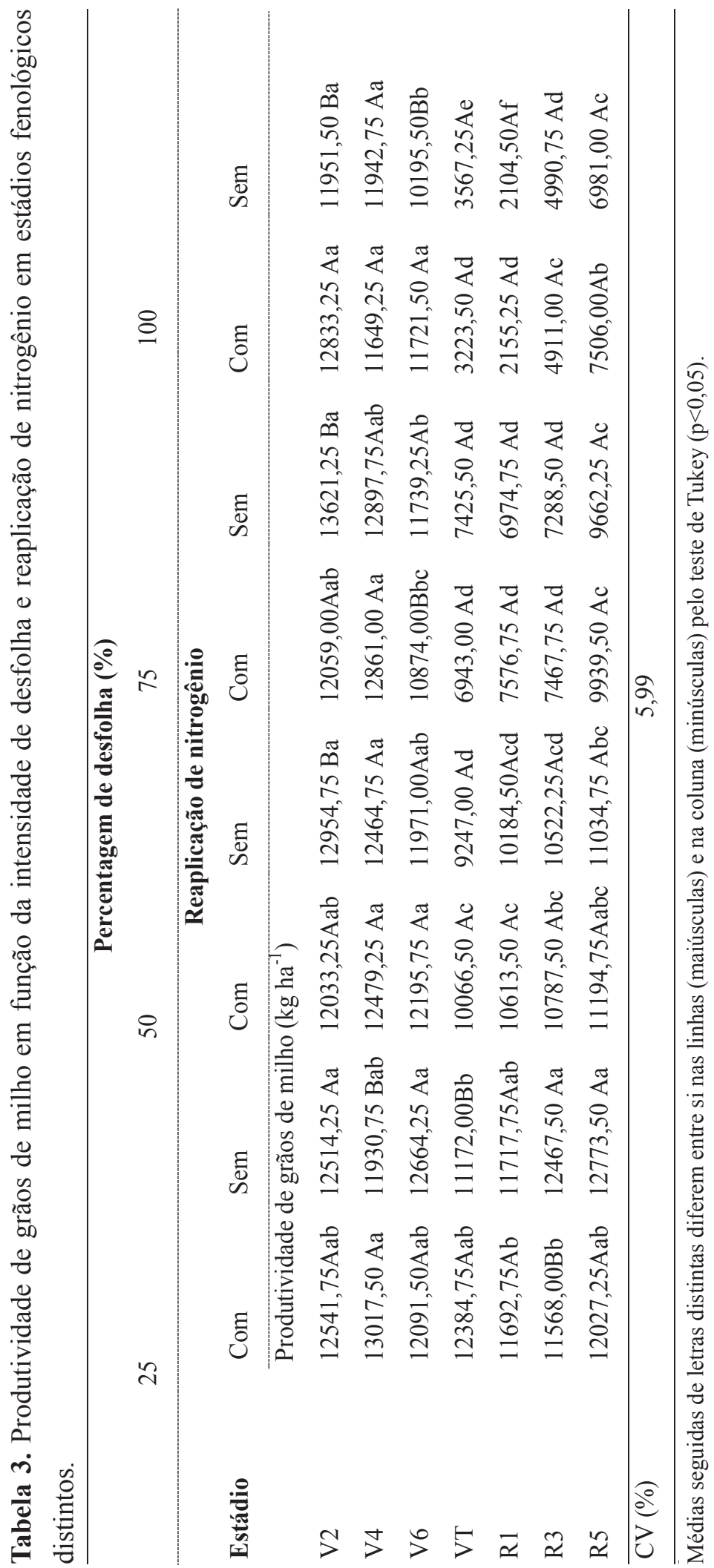


as intensidades de desfolha, pois os componentes de rendimento importantes, como o número e a massa de grãos, estão em formação nessa fase, e não há tempo de restabelecer o equilíbrio fonte-dreno das plantas.

Os resultados obtidos por Sangoi et al. (2014a) concordam com o presente estudo, pois ao avaliarem épocas de desfolha (V8, V15 e VT) e doses de N (0, 50,100 e $200 \mathrm{~kg} \mathrm{ha}^{-1}$ ) também verificaram recuperação das plantas desfolhadas com a reposição de $\mathrm{N}$, mas essa resposta foi observada apenas na fase vegetativa, não havendo efetividade do nutriente após a floração. Efeito semelhante de reposição das estruturas vegetativas com recuperação da produtividade de grãos foi verificado por Modhej et al. (2014), que ao trabalharem com desfolha das folhas superiores e inferiores, assim como com doses crescentes de $\mathrm{N}(0$ a $240 \mathrm{~kg}$ de $\mathrm{N} \mathrm{ha}^{-1}$ ), evidenciaram efeito positivo no reestabelecimento do crescimento das plantas e por consequência da produtividade de grãos por causa da suplementação da fertilização nitrogenada.

Para a produtividade, tratando-se do desdobramento da reaplicação de $\mathrm{N}$ nas diferentes intensidades de desfolha e estádios em que se realizou a desfolha, (Figura 3), constatou-se padrão de redução linear para a maioria dos estádios à medida que se incrementou a intensidade de desfolha, com exceção do estádio V2 e da condição sem reaplicação de N no estádio V4, que demonstraram comportamento quadrático.

Para o estádio V2 (Figura 3a), verificou-se adequação quadrática nas duas condições relacionadas à reaplicação de $\mathrm{N}$. Com a reaplicação de $\mathrm{N}$, houve ponto de máxima resposta em $60 \%$ de desfolha e sem a reaplicação de $\mathrm{N}$ houve ponto de mínima em 59\% de desfolha. Para o estádio V4 (Figura 3b), houve comportamento quadrático na condição sem reaplicação de N, com ponto de máxima resposta em $64 \%$ de desfolha. Para a condição com reaplicação de N, hou- ve adequação linear decrescente, com taxa de decréscimo de $150 \mathrm{~kg}$ para cada $10 \%$ a mais de desfolha. Conforme a desfolha ocorreu em estádios mais avançados do desenvolvimento (V6, VT, R1, R3 e R5), a adequação dos modelos foram lineares decrescentes à medida que se aumentou a intensidade de desfolha (Figura $3 \mathrm{c} \mathrm{d}$ e $\mathrm{f} g$ ).

Destaca-se, no entanto, que em V6 e R5 as taxas de decréscimo da produtividade foram menores do que as verificadas nos estádios VT, R1 e R3. Novamente destacando-se a maior sensibilidade do milho a estresse por desfolhamento nas fases de definição de rendimento de grãos (floração e enchimento de grãos).

Nos estádios em que se verificou o comportamento linear decrescente para produtividade com incremento da intensidade de desfolha (Figura $3 \mathrm{c}, \mathrm{d}$, e, $\mathrm{f}, \mathrm{e}, \mathrm{g}$ ), a taxa de decréscimo do rendimento de grãos foi maior quando não houve a reposição de N. Isso se relaciona ao que foi supramencionado quanto à característica de promoção do desenvolvimento vegetativo e estruturação de área foliar por esse nutriente.

Essa constatação se sustenta pelo favorecimento da redistribuição de fotoassimilados que o $\mathrm{N}$ propicia por causa da sua participação na formação de estruturas vegetativas que dão equilíbrio à relação fonte-dreno nas plantas sob estresse por desfolha, conforme salientado por Modhej et al. (2014) e Sichocki et al. (2014).

Portanto, é pertinente destacar que a desfolha é mais prejudicial quando ocorre entre VT e R3 e que, nessa condição, conforme o incremento da desfolha há decréscimo da produtividade, sendo baixa a eficiência do $\mathrm{N}$ em recuperar danos da desfolha, confirmando o que foi verificado por Sangoi et al. (2014a) para fases anteriores à floração.

Quando se comparam os fatores estudados em parcelas controle conduzidas sem alteração da área 

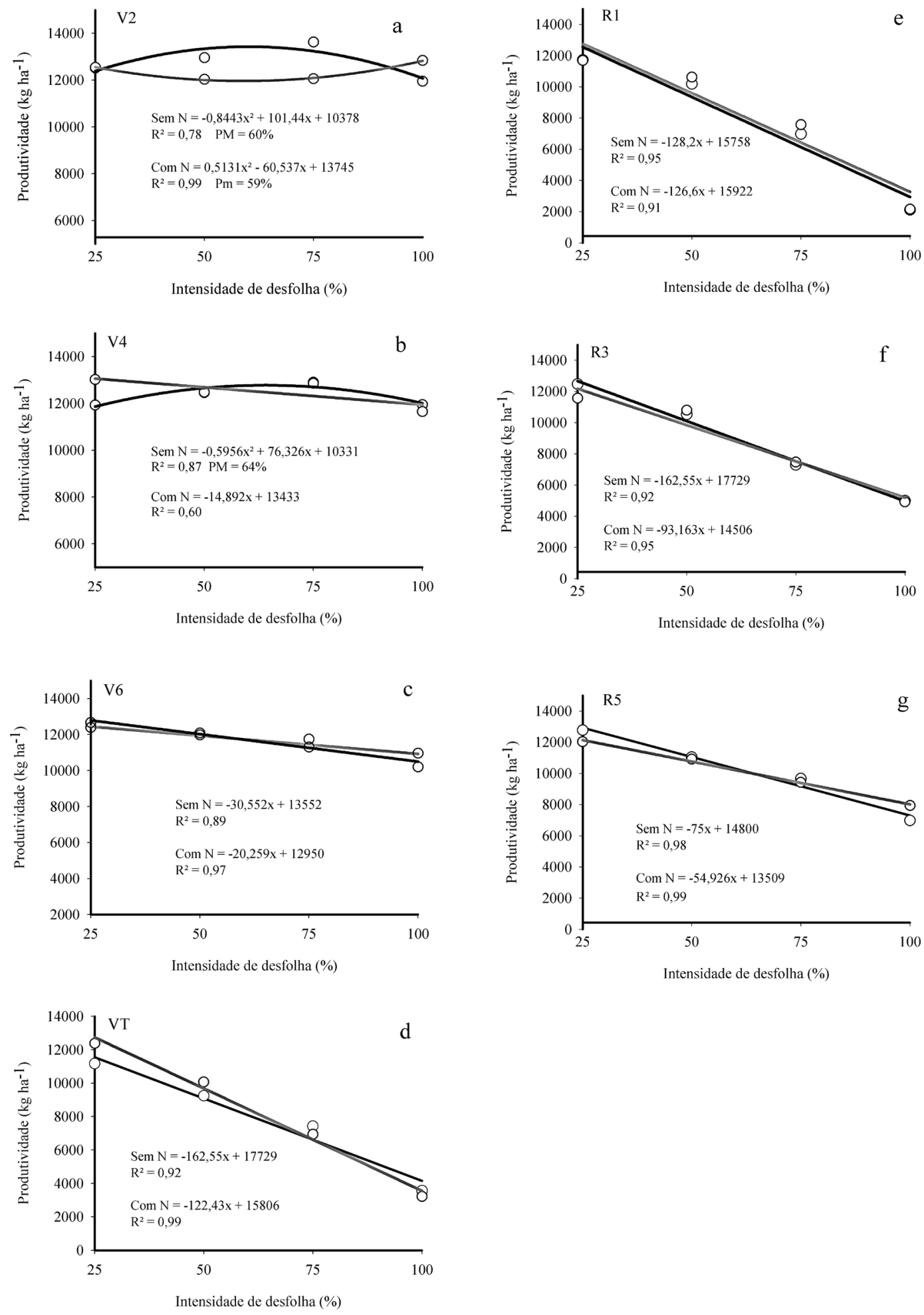

Figura 3. Produtividade de grãos de milho, em função da desfolha realizada nos estádios: V2 (a), V4 (b), V6 (c), VT (d), R1 (e), R3 (f) e R5 (g), com (-) e sem (-) reaplicação de nitrogênio. 
foliar durante todo o ciclo (Tabela 4), constatam-se prejuízos significativos ocasionados pela desfolha. Ao se comparar a condição média das parcelas onde se realizou desfolha e não houve reaplicação de $\mathrm{N}$ com o controle sem desfolha e sem reaplicação de $\mathrm{N}$, há uma diferença média de $24 \%$ aproximadamente na produtividade de grãos.
Essa mesma redução foi encontrada quando comparadas as médias das parcelas com desfolha e com reaplicação de $\mathrm{N}$ com as das parcelas controle sem desfolha e com reaplicação de N. No entanto, a condição com reaplicação de $\mathrm{N}$ partiu de uma condição de produtividade de cerca de $13.500 \mathrm{~kg} \mathrm{ha}^{-1}$, aproximadamente $100 \mathrm{~kg}$ superior à parcela controle

Tabela 4. Produtividade de grãos e redução média de produtividade em função da reaplicação de N, estádios fenológicos e intensidade de desfolha.

\begin{tabular}{lccc}
\hline Fatores comparados & $\begin{array}{c}\text { Produtividade } \\
\left(\mathrm{kg} \mathrm{ha}^{-1}\right)\end{array}$ & $\begin{array}{c}\text { Redução média } \\
\left(\mathrm{kg} \mathrm{ha}^{-1}\right)\end{array}$ & Redução $(\%)$
\end{tabular}

Reaplicação de $\mathrm{N}^{1}$

Sem reaplicação de $\mathrm{N}$

Testemunha sem reaplicação de $\mathrm{N}$

Com reaplicação de $\mathrm{N}$

Testemunha com reaplicação de $\mathrm{N}$

Estádios fenológicos ${ }^{2}$

\begin{tabular}{l} 
V2 \\
V4 \\
V6 \\
VT \\
R1 \\
R3 \\
R5 \\
Testemunha absoluta \\
\hline
\end{tabular}

Intensidade de desfolha $(\%)^{3}$

25

50

75

100
$10177,21 \mathrm{~b}$

$13377,71 \mathrm{a}$

3200,49

23,92

10229,09 b

$13429,59 a$

3200,50

23,83

Testemunha absoluta

$\begin{array}{llr}12760,39 b & 643,26 & 4,79 \\ 12309,02 b & 1094,63 & 8,17 \\ 11642,57 b & 1761,08 & 13,14 \\ 7852,90 b & 5550,75 & 40,28 \\ 7745,42 b & 5526,13 & 34,22 \\ 8817,27 b & 4586,38 & 24,35 \\ 10112,92 b & 3290,73 & 24,34\end{array}$

13403,65 a

Médias seguidas de letras distintas diferem do tratamento testemunha pelo teste de Dunnett $(\mathrm{p}<0,05)$.

Legenda: ${ }^{1}$ comparação entre as condições de reaplicação de nitrogênio com desfolha e suas respectivas testemunhas. ${ }^{2}$ comparação dos estádios fenológicos com desfolha e a testemunha sem desfolha. ${ }^{3}$ comparação das intensidades de desfolha e a testemunha sem desfolha. 
sem $\mathrm{N}$, o que evidencia o favorecimento produtivo do fornecimento suplementar de $\mathrm{N}$ em cobertura para a cultura do milho.

Quando são comparadas as produtividades médias das parcelas desfolhadas com e sem reaplicação de $\mathrm{N}$ e com intensidades distintas de desfolha, com a média dos controles sem desfolha, é nítido o agravamento do prejuízo em rendimento de grãos do milho conforme se avança dos estádios iniciais (vegetativos) que tiveram uma redução média de $10 \%$, para os finais (reprodutivos), com redução máxima verificada de cerca de $40 \%$ no estádio VT, 34\% em R1 e menores danos em R3 e R5, com cerca de 24\%.

No período de floração (VT - R1), ocorre a exteriorização das inflorescências masculina e feminina, bem como a dispersão dos grãos de pólen e fecundação dos óvulos, que iniciam a partir desse momento a fase de multiplicação celular por mitose (Ritchie et al., 1993).

Portanto, essa fase é a mais determinante para obtenção de alta produtividade em milho e ao mesmo tempo é a fase em que mais devem ser evitados estresses, principalmente o mecânico que ocasiona perda de área foliar tão exigida para bom desenvolvimento e correto balanço da relação fonte-dreno nas plantas. Tal afirmação é corroborada por Alvim et al. (2011), Pereira et al. (2012) e Lima et al. (2010).

Já em função das intensidades de desfolha, a perda de produtividade das parcelas que tiveram desfolhamento em relação à média dos controles sem perda de área foliar atende a um comportamento inverso, ou seja, quanto maior a desfolha, menor a produtividade de grãos. A menor intensidade de desfolha $(25 \%)$ reduziu em $9 \%$ o rendimento de grãos e a retirada total das folhas (100\%) chegou a reduzir em $44 \%$ a produtividade do milho.
Essa resposta era esperada, pois quanto maior o dano ao aparato fotossintético, menor é a eficiência de assimilação de carbono pelas plantas e por consequência menor é a produção de carboidratos, com comprometimento da fotossíntese líquida. Isso reduz a energia disponível para o metabolismo primário das plantas de milho, que respiram menos e como consequência reduzem a formação de componentes essenciais ao seu crescimento e desenvolvimento, como por exemplo lignina que é um composto formador de parede celular e é sintetizado pelo metabolismo secundário do vegetal.

Portanto, por menor que seja a redução da área foliar das plantas de milho, essa é suficiente para comprometer a sua eficiência fotossintética e por consequência a sua relação fonte-dreno e a distribuição de fotoassimilados, reduzindo por sua vez a produtividade final de grãos. Danos semelhantes ao rendimento de grãos do milho foram encontrados em trabalhos realizados por Viecelli et al. (2011) e Rezende et al. (2015).

Quanto à percentagem de grãos ardidos (Tabela 5), o desdobramento das condições de reaplicação de $\mathrm{N}$ e estádios fenológicos em que se realizou a desfolha demonstrou superioridade da condição sem reaplicação no estádio V4.

Na comparação entre os estádios em que houve a desfolha e não foi realizada a reaplicação de $\mathrm{N}$, maior percentagem de grãos ardidos foi verificada quando a desfolha ocorreu no início do ciclo V4 e V6 até o florescimento (VT). Para a condição de desfolha com reaplicação de $\mathrm{N}$, adicionam-se a esses os estádios V2 e R1, aumentando o intervalo de maior ocorrência dos grãos ardidos (Tabela 5).

A maior intensidade de grãos ardidos que ocorreu nas fases iniciais em que se desfolhou, e principalmente quando houve reaplicação do $\mathrm{N}$, é justifi- 
cada pela recuperação da área foliar das plantas, que gerou maior fechamento do dossel e por consequência menor ventilação e incidência de radiação solar.

Esses fatores proporcionaram a criação de microclima favorável ao desenvolvimento de fungos fitopatogênicos que inicialmente infectam as estruturas vegetativas e passam para a espiga e grãos ao fim do ciclo, causando deterioração e reduzindo sua qualidade (Lanza et al., 2016). Brito (2010) observou que o microclima úmido dentro do dossel proporciona condições favoráveis à infecção dos fungos causadores de grãos ardidos, e situações como altas densidades de plantas e/ou outras que diminuam a circulação de ar no dossel foliar na cultura do milho podem agravar esse problema fitopatológico.

Perdas evidentes da massa de grãos e o do rendimento por área podem ser evitadas se houver medidas preventivas aos fatores estressantes, como a desfolha por insetos, que pode ser evitada com o manejo integrado de pragas na cultura. No entanto, a suplementação com $\mathrm{N}$ é uma possibilidade para mitigar parcialmente os efeitos maléficos do desfolhamento, em razão da efetividade desse nutriente em favorecer o crescimento vegetal, fazer parte de dos aminoácidos livres e proteicos, bases nitrogenadas (purinas e pirimidinas) e os ácidos nucleicos.

Nas folhas, o nitrogênio está nos cloroplastos como constituinte da molécula de clorofila, e também participa da síntese de vitaminas, hormônios, coenzimas, alcaloides, hexosaminas e outros compostos. Portanto, sua essencialidade para o crescimento e desenvolvimento vegetal é notória, e ressalta-se que a maior efetividade da adubação nitrogenada em reverter danos causados pela desfolha ocorre nos estádios vegetativos do milho, pois favorece a manutenção da área foliar e a formação dos componentes de produção.

Tabela 5. Percentagem de grãos ardidos, em função da intensidade de desfolha e reaplicação de nitrogênio em estádios fenológicos distintos.

\begin{tabular}{ccc}
\hline \multirow{2}{*}{$\begin{array}{c}\text { Estádio } \\
\text { fenológico }\end{array}$} & \multicolumn{2}{c}{ Reaplicação de nitrogênio (kg ha $\left.\mathbf{~}^{\mathbf{1}}\right)$} \\
\cline { 2 - 3 } & \multicolumn{3}{c}{ Sem } & Grãos ardidos $(\%)$ \\
\hline V2 & $15,94 \mathrm{bcA}$ & $15,75 \mathrm{abA}$ \\
V4 & $22,06 \mathrm{aA}$ & $15,81 \mathrm{abB}$ \\
V6 & $18,31 \mathrm{abA}$ & $14,44 \mathrm{abA}$ \\
VT & $19,25 \mathrm{abA}$ & $19,63 \mathrm{aA}$ \\
R1 & $11,38 \mathrm{cdA}$ & $13,69 \mathrm{abA}$ \\
R3 & $8,75 \mathrm{dA}$ & $12,00 \mathrm{bcA}$ \\
R5 & $9,69 \mathrm{dA}$ & $6,56 \mathrm{cA}$ \\
\hline
\end{tabular}

Médias seguidas de letras distintas diferem entre si nas linhas (maiúsculas) e na coluna (minúsculas) pelo teste de Tukey a 5\% de probabilidade. 


\section{Conclusões}

A reaplicação de nitrogênio após a desfolha atenua os efeitos desse estresse na massa e no rendimento total de grãos, com maior efetividade quando a redução da área foliar ocorre nos estádios vegetativos.

O prejuízo ao desempenho produtivo em razão da desfolha é acentuado quando ocorre nas fases de florescimento e de enchimento de grãos, pois desequilibra a relação fonte-dreno. A produtividade de grãos é comprometida com o aumento da intensidade de desfolha.

A desfolha em estádios iniciais proporciona maior intensidade de grãos ardidos nas plantas de milho.

\section{Referências}

ALVIM, K. R. T.; BRITO, C. H.; BRANDÃO, A. M.; GOMES, L. S.; LOPES, M. T. G. Redução da área foliar em plantas de milho na fase reprodutiva. Revista Ceres, Viçosa, MG, v. 58, n. 4, p. 413-418, 2011.

DOI: 10.1590/S0034-737X2011000400002.

BLUM, L. E. B.; SANGOI, L.; AMARANTE, C. V. T. do; ARIOLI, C. J.; GUIMARÃES, L. S. Desfolha, população de plantas e precocidade do milho afetam a incidência e a severidade de podridões de colmo. Ciência Rural, Santa Maria, v. 33, n. 5, p. 805-812, 2003.

DOI: $10.1590 / \mathrm{S} 0103-84782003000500003$.

BRASIL. Ministério da Agricultura e Pecuária e Abastecimento. Regras para análise de sementes. Brasília, DF, 2009. 399 p.

BRASIL. Portaria n ${ }^{\circ} 11$, de 12 de abril de 1996. Critérios complementares para classificação do milho. Diário Oficial da União, Brasília, DF, n. 72, 1996. Disponível em: $\quad<$ http://www.codapar.pr.gov.br/arquivos/File/pdf/ milho11_96.pdf $>$. Acesso em: 10 fev. 2017.
BRITO, A. H. Controle genético e químico de doenças foliares e grãos ardidos em milho. 2010. 88 f. Tese (Doutorado em Fitotecnia) - Universidade Federal de Lavras, Lavras, 2010.

BRITZ, G. D. The effect of defoliation at various growth stages on maize grain yield. Crop Production, v. 11, p. 85-89, 1982.

CRUZ, J. C.; PEREIRA FILHO, I. A.; QUEIROZ, L. R. Milho: cultivares para 2013/2014. Sete Lagoas: Embrapa Milho e Sorgo, 2016. Disponível em: <http://www.cnpms. embrapa.br/milho/cultivares $>$. Acesso em: 3 fev. 2017.

KAPPES, C.; ANDRADE, J. A. C.; ARF, O.; OLIVEIRA, A. C.; ARF, M. V.; FERREIRA, J. P. Arranjo de plantas para diferentes híbridos de milho. Pesquisa Agropecuária Tropical, v. 41, n. 3, p. 348-359, 2011. DOI: $10.5216 /$ pat.v41i3.9650.

LANZA, F. E.; ZAMBOLIM, L.; COSTA, R. V.; SILVA, D. D.; QUEIROZ, V. A. V.; PARREIRA, D. F.; MENDES, S. M.; SOUZA, A. G. C.; COTA, L. V. Aplicação foliar de fungicidas e incidência de grãos ardidos e fumonisinas totais em milho. Pesquisa Agropecuária Brasileira, Brasília, DF, v. 51, n. 5, p. 638-646, 2016.

DOI: 10.1590/S0100-204X2016000500026.

LIMA, T. G.; VON PINHO, R. G.; BRITO, A. H.; VON PINHO, E. V. R. Consequências da remoção do limbo foliar em diferentes estádios reprodutivos da cultura do milho em duas épocas de semeadura. Bragantia, Campinas, v. 69, n. 3, p. 563-570, 2010.

DOI: $10.1590 / \mathrm{S} 0006-87052010000300007$.

MAGAlhães, P. C.; DURÃES, F. O. M. Fisiologia da produção de milho. Sete Lagoas: Embrapa Milho e Sorgo, 2006. 10 p. (Embrapa Milho e Sorgo. Circular Técnica, 76).

MAGAlHÃES, J. A.; SOUZA CARNEIRO, M. S.; ANDRADE, A. C.; PEREIRA, E. S.; ANDRADE, A. P.; BAKKE, O.A.; RODRIGUES, B. H. N.; MOCHELFILHO, W. J. E; COSTA, N. L. Características morfogênicas e estruturais do capim-andropogon sob irrigação e adubação. 
Semina: Ciências Agrárias, Londrina, v. 34, n. 5, p. $2427-$ 2436, 2013.

DOI: $10.5433 / 1679-0359.2013 v 34 n 5 p 2427$.

MALAVOLTA, E.; VITTI, G. C.; OLIVEIRA, S.A. Avaliação do estado nutricional das plantas: princípios e aplicações. Piracicaba: Potafós, 1997. 319 p.

MODHEJ, A.; LACK, S.; SORKHI, F. K. G. Effect of nitrogen and defoliation on assimilate redistribution and grain yield of maize (Zea mays L.) under subtropical conditions. Proceedings of the National Academy of Sciences, India Section B: Biological Sciences, v. 84, n. 3, p. 765-770, 2014.

DOI: 10.1007/s40011-014-0315-x.

OKUMURA, R. S.; MARIANO, D. C.; ZACCHEO, P. V. C. Uso de fertilizante nitrogenado na cultura do milho: uma revisão. Revista Brasileira de Tecnologia Aplicada nas Ciências Agrárias, Guarapuava, v. 4, n. 2, p. 226-244, 2011.

DOI: 10.5777/PAeT.V4.N2.13.

PEREIRA, M. J. R.; BONAN, E. C. B.; GARCIA, A.; VASCONCELOS, R. L.; GÍACOMO, K. S.; LIMA, M.

F. Características morfoagronômicas do milho submetido a diferentes níveis de desfolha manual. Revista Ceres, Viçosa, MG, v. 59, n. 2, p. 200-205, 2012.

DOI: 10.1590/S0034-737X2012000200008.

QUEIROZ, A. M. D. E.; SOUZA, C. H. E.; MACHADO, V. J.; LANA, R. M. Q.; KORNDORFER, G. H.; SILVA, A. A. Avaliação de diferentes fontes e doses de nitrogênio na adubação da cultura do milho (Zea mays L.). Revista Brasileira de Milho e Sorgo, Sete Lagoas, v. 10, n. 3, p. 257-266, 2011.

DOI: 10.18512/1980-6477/rbms.v10n3p257-266.

REZENDE, W. S.; BRITO, C. H.; BRANDÃO, A. M.; FRANCO, C.J. F.; FERREIRA, M. V.; FERREIRA, A. S. Desenvolvimento e produtividade de grãos de milho submetido a níveis de desfolha. Pesquisa Agropecuária Brasileira, Brasília, DF, v. 50, n. 3, p. 203-209, 2015.

DOI: 10.1590/S0100-204X2015000300003.
RITCHIE, S. W.; HANWAY, J. J.; BENSON, G. O. How a corn plant develops. Iowa: Iowa State University, 1993. 21 p. (Special Report, 48).

SANGOI, L.; LECH, V. A.; RAMPAZZO, C.; GRACIETTI, L. C. Acúmulo de matéria seca em híbridos de milho sob diferentes relações entre fonte e dreno. Pesquisa Agropecuária Brasileira, Brasília, DF, v. 37, n. 3, p. 259267, 2002.

DOI: 10.1590/S0100-204X2002000300005.

SANGOI, L.; PICOLI JÚNIOR, G. J.; VARGAS, V. P.; VIEIRA, J.; SCHMITT, A.; ZOLDAN, S. R.; SIEGA, E.; CARNIEL, G. Cobertura nitrogenada como estratégia para reduzir os prejuízos da desfolha em diferentes estádios fenológicos do milho. Semina: Ciências Agrárias, Londrina, v. 35, n. 2, p. 671-682, 2014a.

DOI: $10.5433 / 1679-0359.2014 v 35 n 2 p 671$.

SANGOI, L.; SCHMITT, A.; SILVA, P. R. F. da; VARGAS, V. P.; ZOLDAN, S. R.; VIEIRA, J.; SOUZA, C. A.; PICOLI JUNIOR, G. J.; BIANCHET, P. Perfilhamento como característica mitigadora dos prejuízos ocasionados ao milho pela desfolha do colmo principal. Pesquisa Agropecuária Brasileira, Brasília, DF, v. 47, n. 11, p. 1605-1612, 2012.

DOI: $10.1590 / \mathrm{S} 0100-204 X 2012001100007$.

SANGOI, L.; VIEIRA, J.; SCHENATTO, D. E.; GIORDANI, W.; BONIATTI, C. M.; IGNA, L. D. ARRUDA, C. E. S.; ZANELLA, J. Tolerância à desfolha de genótipos de milho em diferentes estádios fenológicos. Revista Brasileira de Milho e Sorgo, Sete Lagoas, v. 13, n. 3, p. 300-311 2014b.

DOI: 10.18512/1980-6477/rbms.v13n3p300-311.

SANTOS, H. G. dos; JACOMINE, P. K. T.; ANJOS, L. H. C. dos; OLIVEIRA, V. A. de; LUMBRERAS, J. F.; COELHO, M. R.; ALMEIDA, J. A. de; CUNHA, T. J. F.; OLIVEIRA, J. B. de. Sistema brasileiro de classificação de solos. 3. ed. rev. e ampl. Brasília, DF: Embrapa, 2013. $353 \mathrm{p}$.

SICHOCKI, D.; GOTT, R. M.; FUGA, C. A. G.; AQUINO, L. A.; RUAS, R. A. A.; NUNES, P. H. M. P. Resposta do 
milho safrinha à doses de nitrogênio e de fósforo. Revista Brasileira de Milho e Sorgo, Sete Lagoas, v. 13, n. 1, p. 4858, 2014. DOI: 10.18512/1980-6477/rbms.v13n1p48-58.

TROGEllo, E.; GOTT, R. M.; FUGA, C. A. G.; AQUINO, L. A.; RUAS, R. A. A.; NUNES, P. H. M. P.

Respostas morfoagronômicas de milho submetido a desfolha artificial. Revista Brasileira de Milho e Sorgo, Sete Lagoas, v. 16, n. 3, p. 460-468, 2017.

DOI: 10.18512/1980-6477/rbms.v16n3p460-468.
UHART, S. A.; ANDRADE, F. H. Nitrogen and carbon accumulation and remobilization during grain filling in maize under different source and sink ratios. Crop Science, Madison, v. 35, p. 183-190, 1995.

DOI: $10.2135 /$ cropsci1995.0011183X003500010034x.

VIECELLI, C. A.; FILLWOCK, J. M.; SUZIN, V. Efeito do desfolhamento das plantas na produtividade do milho. Revista Brasileira de Tecnologia Aplicada nas Ciências Agrárias, Guarapuava, v. 4, n. 3, p. 179-190, 2011. 